
Revue Revue de l'histoire des religions
de Ihistoire des religions
$1 \mid 2019$
Corps, ascèse et extinction dans l'histoire du bouddhisme (Inde, Corée, Japon)

\title{
Saākyamuni émacié ou la critique de la pratique des austérités
}

The emaciated Sáakyamuni or criticism of austere practices

\section{Guillaume Ducœur}

\section{(2) OpenEdition}

\section{Journals}

Édition électronique

URL : https://journals.openedition.org/rhr/9379

DOI : $10.4000 /$ rhr.9379

ISSN : 2105-2573

Éditeur

Armand Colin

Édition imprimée

Date de publication : 1 mars 2019

Pagination : 11-40

ISBN : 978-2-200-93230-5

ISSN : 0035-1423

Référence électronique

Guillaume Ducœur, "Śākyamuni émacié ou la critique de la pratique des austérités », Revue de

l'histoire des religions [En ligne], 1 | 2019, mis en ligne le 01 janvier 2022, consulté le 08 janvier 2022.

URL : http://journals.openedition.org/rhr/9379 ; DOI : https://doi.org/10.4000/rhr.9379 


\section{Śākyamuni émacié ou la critique de la pratique des austérités}

L'épisode des six années d'austérité pratiquées par Śākyamuni a été souvent regardé comme l'abandon historique de l'ascétisme rigoriste des śramaña par le Buddha lui-même. La présente étude revient donc sur la construction de cet épisode célèbre en Inde qui inspira nombre d'artistes et qui touche au problème du rejet du second extrême dans la voie médiane telle qu'elle est définie dans les sūtra et vinaya des écoles du sthaviravāda. Il apparaît finalement que cette critique, voire cette condamnation, de la pratique des austérités s'enracine plutôt dans une transformation historique du samgha bouddhique pour lequel la sédentarisation progressive dans des structures monastiques eut pour conséquence l'abandon de la vie forestière et la prééminence de la pratique de la connaissance discernante sur la pratique corporelle.

\section{The emaciated Śākyamuni or criticism of austere practices}

The episode describing the six years of austerity undergone by Śäkyamuni has often been seen as the historical break with the rigorist asceticism of the śramana by the Buddha himself. This paper looks once more at the construction of this episode, which is very well known in India and inspired a number of artists, and which touches on the problem of the rejection of the second extreme in favour of a middle way, as defined in the sūtra and vinaya of the sthaviravāda schools. In fact, it seems that the criticism, or condemnation, of austere practices is instead rooted in a historic transformation of the Buddhist samgha, for whom progressive sedenterisation within monastic structures resulted in giving up life in the forest and in giving priority to practices aimed at obtaining discerning knowledge over corporal practices. 
En 1844, dans son Introduction à l'histoire du buddhisme indien, Eugène Burnouf (1801-1852) déclarait au sujet de l'épisode de la pratique des austérités entreprise par Śākyamuni durant six années que "Çâkyamuni, ou le solitaire de la race de Çâkya, ne se distingue pas, à l'origine, des autres solitaires de race brahmanique $»^{1}$. Si nous admettons que les sources biographiques bouddhiques relatent la vie historique du fondateur, notamment ici, avant son éveil, il convient alors d'accepter une telle remarque, à l'exemple d'Hermann Oldenberg (1854-1920) qui professait "l'opinion que nous possédons dans le récit de la manière dont le descendant des Sakyas est devenu le Bouddha, un véritable fragment d'histoire $»^{2}$.

À l'inverse, si nous considérons que ces biographies cherchent à présenter le Buddha comme bhikșu idéaltypique et qu'elles illustrent donc des points importants de la doctrine des écoles bouddhiques qui sont à l'origine de leur composition, il devient alors nécessaire de s'interroger sur la place d'un tel épisode dans l'économie de ces biographies complètes ou partielles et sur sa résonance dans l'histoire du développement de la doctrine bouddhique elle-même. Or, cet épisode narrant les pratiques extrêmes de l'arrêt de l'activité mentale, de la rétention du souffle respiratoire et du jeûne touche à la représentation que se faisaient certains bhikșu du corps et de sa possible médiation ou non dans l'obtention de la cessation (nirodha) ou de l'extinction (nirvāṇa) de tout désir (tṛ̣ṇāa) et par conséquent de toute souffrance (duhkha). En d'autres termes, un corps vivifié par la pratique des mortifications pourrait-il amener son auteur à l'acquisition d'un corps vivifiant par l'intermédiaire duquel la voie suprême du nirvāṇa serait atteinte ? Ou bien, cette apparente vivification corporelle en serait-elle un obstacle et n'aboutirait-elle qu'à l'exténuation du pratiquant?

C'est assurément tout l'enjeu doctrinal qui transparaît dans cet épisode de la vie du fondateur et qui témoigne des tensions

1. Eugène Burnouf, Introduction à l'histoire du buddhisme indien, tome I, Paris, Imprimerie royale, 1876, p. 137 (1 ${ }^{\text {re }}$ éd. 1844).

2. Hermann Oldenberg, Le Bouddha, sa vie, sa doctrine, sa communauté, Paris, F. Alcan, 1903, p. 115. 
entre courants bouddhiques en un temps où de telles pratiques s'organisaient progressivement en système sotériologique en dehors même de la communauté bouddhique, à l'exemple du yoga, et qui concurrençait au sein du samgha une autre approche, celle de la connaissance spéculative et discernante ou prajñā.

La présente contribution vise donc à explorer moins l'évidente concurrence entre communauté bouddhique (samgha) et courants ascétiques non bouddhiques que les possibles historiques des positionnements doctrinaux et ascétiques de certaines écoles bouddhiques anciennes au sein du saṃgha même. La difficulté de restituer l'histoire rédactionnelle d'un tel épisode réside avant tout dans le caractère lacunaire des Sūtra et Vinaya des écoles bouddhiques anciennes quand ceux-ci ne sont pas tout simplement définitivement perdus. Et si opposition il y eut entre religieuxmendiants bouddhistes (bhikṣu), nous n'avons plus accès aujourd'hui qu'aux seuls écrits de ceux qui pratiquèrent, non pas un ascétisme rigoriste pour lequel l'écrit n'avait aucune finalité première, mais la seule connaissance discernante.

Afin d'entrer dans cette hypothétique restitution historique de l'épisode de la pratique des austérités, nous présenterons brièvement les sources textuelles et iconographiques s'y rapportant, la structure récurrente dudit épisode, puis les critiques à l'encontre des ascètes non bouddhistes et implicitement des bhikṣu s'adonnant aux mortifications au sein du samgha. Ces diatribes furent à l'origine de la construction de ce passage de la vie du fondateur du bouddhisme tel qu'il est aujourd'hui conservé dans les sources textuelles des écoles anciennes et du mahāyāna ainsi que représenté sur des bas-reliefs ou dans la statuaire.

\section{SOURCES TEXTUELLES ET ICONOGRAPHIQUES}

L'épisode de la pratique des austérités (dukkarakārikā, duṣkaracaryā) est présent tout autant dans les Sūtra et les Vinaya des écoles sthaviravāda et des Mahāsāṃghika que dans les biographies du mahāyāna voire des œuvres poétiques tel le Buddhacarita d'Aśvaghoșa. De ce fait, les genres littéraires sont pluriels tout comme les récits-cadres ainsi que la liste des mortifications pratiquées. 
Pour les écoles du sthaviravāda et plus particulièrement pour la branche des Distinctionnistes ou Vibhajyavādin, l'épisode se trouve, chez les Theravādin, dans deux Sutta du Majjhimanikāya, à savoir le Mahāsaccakasutta ${ }^{3}$ et le Bodhirājakumārasutta ${ }^{4}$, et, chez les Dharmaguptaka, dans leur Vinaya conservé en traduction chinoise (四分律, Sifen lü, Caturvargikavinaya) réalisée au début $\mathrm{du} \mathrm{V}^{\mathrm{e}} \mathrm{s}$. apr. J.-C. sous la direction de Buddhayaśas (佛陀耶舍, Fotuoyeshe), simplement par une brève allusion: "Lorsque le Bodhisattva arriva à cet endroit, il pratiqua les austérités durant six années. Malgré cela, il ne put réaliser la doctrine suprême de la noble connaissance supérieure $»^{5}$. Comme le notait André Bareau (1921-1993), c'est donc probablement l'école du Theravāda qui fut à l'origine de l'épisode dans sa version longue ${ }^{6}$, mais dont néanmoins les récits-cadres diffèrent selon les Sutta.

Dans le Mahāsaccakasutta, en effet, le Buddha, séjournant à Vaiśāli, réfute les propos que lui tient le jaïna Saccaka au sujet du développement du corps (kāyabhāvana) et de la pensée (cittabhāvana), accusant les disciples du Buddha de ne pratiquer que le seul développement de la pensée au détriment de celui du corps. Dans le Bodhirājakumārasutta, le Buddha, séjournant à Śuśumāragira dans le pays des Bhaggā, accepta de prendre son repas avec le prince Bodhi, fils du roi Udena de Kauśāmbī, qui lui livra sa pensée : «Le bonheur ne doit pas être obtenu par le bonheur. Le bonheur doit être obtenu par la souffrance $»^{7}$. Dans les deux cas, le Buddha leur narra sa quête de la voie menant à l'éveil, depuis sa sortie du foyer familial et sa rencontre avec Ārāḍa Kālāma et Udraka Rāmaputra, l'énonciation de trois comparaisons jusqu'à sa résolution de réprimer graduellement sa pensée, de retenir totalement sa respiration puis de pratiquer des jeûnes de plus en plus difficiles à supporter. Ainsi, le même épisode a été utilisé à deux reprises pour

3. P[ali] T[ext] S[ociety], [M]ajjhima[N]ikaya, vol. 1, sutta 36, p. 235-251.

4. PTS, MN, vol. 2, sutta 85, p. 91-97.

5. 時菩薩即於彼處六年苦行. 雖爾猶不證増上聖智勝法, shí púsà jí yúbǐchù liùnián kǔxíng. suī ěr yóu bùzhèng zēngshàng shèngzhì shèng fă. T[aishō Shinshū Daizōkyō] 1428, vol. 22, p. 781a.3-4.

6. André Bareau, Recherches sur la biographie du Buddha dans les Sütrapițaka et les Vinayapitaka anciens: De la quête de l'éveil à la conversion de Śāriputra et de Maudgalyāyana, Paris, École française d'Extrême-Orient, 1963, p. 49.

7. na kho sukhena sukhaṃ adhigantabbam dukkhena kho sukham adhigantabban, PTS, MN, vol. 2, sutta 85, p. 93. 
justifier deux positionnements bouddhiques touchant à des domaines différents, l'un défendant la pratique du développement de la pensée consciente dans le cadre de l'ascétisme et plus généralement du mode de vie des śramaṇa, l'autre réfutant l'idée qu'il faille souffrir pour atteindre le bonheur même pour des dévots bouddhistes (upāsaka).

Cette pratique des mortifications est également présente dans la partie introductive ou «exposé des occasions [des bonnes actions répétées] » (nidanakathā) du recueil des Jātaka, ou des Naissances [antérieures du Bodhisattva], classé dans le Khuddakanikāya du Suttapitaka. Il s'agit d'un condensé de la version du Sutta du Majjhimanikāya qui a été rédigé vers le $\mathrm{V}^{\mathrm{e}} \mathrm{s}$. apr. J.-C. Néanmoins, seule la pratique du jeûne est mentionnée. Quant au Lomahamsajātaka ${ }^{8}$, celui-ci relate comment, lors d'une de ses vies antérieures, le Bodhisattva fut amené, afin d'éprouver l'échauffement ascétique non-bouddhique (bāhirakatapam), à être un ājīvika, mangeant très peu, vivant nu en plein air et supportant les morsures du froid en hiver et les brûlures du soleil en été. La gāthā centrale autour de laquelle a été développé ce jātaka exprime à elle seule l'inutilité de ces austérités : "Brûlé, gelé, seul dans des bois terrifiants, nu, sans aucun feu tout en étant [lui-même un feu intérieur], attaché au désir, [tel] est l'ascète $»^{9}$. Exténué, le Bodhisattva au moment de mourir eut la vision des enfers qui l'attendaient et réalisant l'inanité de toutes ces mortifications, abandonna cette fausse doctrine pour saisir la vue correcte (sammādițthiṃ gahetvā) de la vérité, et ainsi renaître au monde des dieux (devaloke nibbatti). Le récit-cadre explicatif (jātakațhavaṇnanā) met en scène, quant à lui, son ancien disciple Sunakkhatta qui le quitta pour suivre la voie ascétique du rigoriste Kora le Kṣatriya, puis vint à Pāṭikārāma près de Vaiśāli pour médire sur la doctrine du Buddha en clamant que cette dernière ne peut conduire à la destruction de la souffrance. Ce à quoi le Buddha rétorqua en racontant cette existence antérieure, vécue quatre-vingtonze kalpa plus tôt, et comment il abandonna l'ascétisme après être devenu émacié à l'extrême (lūkho sudam homi paramalūkho) à force de mortifications. Cette introduction explicative, qui date du

8. PTS, Jātaka, vol. 1, jātaka 94, p. 389-391.

9. sotatto sosîto eko bhiṃsanake vane naggo na c'aggim āsīno esanāpasuto munīti. PTS, Jātaka, vol. 1, jātaka 94, p. 390. 
$\mathrm{V}^{\mathrm{e}} \mathrm{s}$. apr. J.-C., fait référence à l'état d'exténuation de Śākyamuni tel qu'il est évoqué dans les Sutta du Majjhimanikāya.

La version développée de la rétention de la pensée et de la respiration ainsi que de la pratique du jeûne est également présente dans le Vinaya des Mūlasarvāstivādin, dont l'école remonte probablement au IV s. apr. J.-C., ou Mūlasarvāstivādavinayasamghabhedavastu ${ }^{10}$ traduit en chinois par Yijing 義淨 (635-713) sous les Tang. Le Mūlasarvāstivādavinayakșudrakavastu ${ }^{11}$ que Yijing traduisit également n'en fait, quant à lui, qu' une brève allusion.

Il est bien difficile de dater ces différentes sources textuelles, mais nous pouvons admettre, en suivant l'avis d'A. Bareau, que cet épisode présent dans les Sutta et les Jātaka du theravāda, ainsi que sa brève allusion désintéressée chez les Dharmaguptaka, école influente dans les territoires du Nord-Ouest indien au $\mathrm{I}^{\text {er }}$ s. apr. J.-C., et sa conservation dans le Vinaya de la branche tardive des Sarvāstivādin, "a été imaginé assez tard [...]. Il n’y a pas là la moindre trace d'un souvenir quelconque, rien que le produit de l'imagination de savants docteurs visant, non pas à conserver la mémoire d'un exploit accompli réellement par le Bienheureux, mais à soutenir un point de doctrine en utilisant, selon un procédé qui leur était cher, le personnage du Buddha, source de toute autorité en matière d'enseignement $»^{12}$. Quoi qu'il en soit, les écoles issues du sthaviravāda et plus particulièrement de la seule branche des Vibhajyavādin conservaient et transmettaient cet épisode de la vie de leur fondateur à travers différents récitscadres relevant soit des Sūtra soit des Vinaya voire des Jātaka. Il en ressort que ces pratiques ascétiques ont été mises en rapport avec le mode de vie des jaïna et des àjīvika tout autant qu'avec la classe sociale des kṣatriya et les laïcs.

Parmi la branche des écoles mahāsāmnghika, celle des Lokottaravādin a inclus, dans son Mahāvastu, l'épisode de la pratique des austérités, très proche de celui des deux Sutta des Theravādin. Ce dernier se situe également après la rencontre de Śākyamuni avec Ārāḍa Kālāma et Udraka Rāmaputra (Mhv 2.118-120) ainsi

10. Gēnbèn shuōyīqiè yǒubù pínàiyé pòsēng shì, 根本説一切有部毘奈耶破僧 事, T. 1450, vol. 24, p. 120a1-c16.

11. Gēnbèn shuōyìqiè yǒubù pínàiyé záshì, 根本説一切有部昆奈耶雜事, T. 1451, vol. 24, p. 299a19 et 299c18.

12. André Bareau, Recherches sur la biographie du Buddha..., p. 49-50. 
qu'après les trois comparaisons ou analogies (Mhv 2.121-123.10). Si la fixation du Mahāvastu par l'école des Supramondanistes ne remonte pas, quant à elle, avant le $\mathrm{V}^{\mathrm{e}} \mathrm{s}$. apr. J.-C., il n'en demeure pas moins que son auteur ou ses auteurs ont repris l'épisode chez les Theravādin ou l'ont puisé à la même source que ces derniers. S'y retrouvent donc les rétentions de la pensée et de la respiration, mais sans degré de difficulté, ainsi que la pratique de jeûnes successifs. À la grande différence des genres littéraires propres aux sources des écoles du sthaviravāda, cet épisode chez les Lokottaravādin s'insère dans leur Vinaya relevant néanmoins d'une biographie plus ou moins continue du Buddha.

En l'état actuel des textes bouddhiques, les seuls éléments de datation sûrs demeurent et le Buddhacarita d'Aśvaghoșa et les biographies complètes ou partielles en langues indiennes dont les traductions chinoises sont datées. Le brāhmane Aśvaghoșa, originaire de la ville de Sāketa au Kośala et converti au bouddhisme par le bhikṣu Pārśva, fut le premier, dans la première moitié du II $^{\mathrm{e}}$ S. apr. J.-C., à avoir composé une biographie complète du Buddha, de sa naissance à sa mort, en sanskrit classique, entièrement versifiée et respectant la poétique sanskrite. Des vingt-huit chapitres de ce Buddhacarita, conservé en traduction chinoise, œuvre de Dharmakșema ${ }^{13}$ en 420 apr. J.-C., seuls quatorze en langue originale ont été conservés jusqu'à nos jours. À l'égal des Dharmaguptaka, Aśvaghoṣa fit peu de cas de l'épisode de la pratique des austérités. Comme pour les versions longues des Theravādin et des Mahāsāṃghika, cet épisode suit la visite que Śākyamuni rendit à Ārāọa Kālāma et Udraka Rāmaputra. Néanmoins, l'auteur, issu du varṇa brāhmanique, développa à souhait la rencontre avec le muni Ārāḍa en composant quatre-vingt-trois strophes contre quatre pour celle avec le muni Udraka, et consacra huit strophes seulement à l'échauffement ascétique (tapas). Il est intéressant de noter qu'Aśvaghoșa n'avait connaissance, semble-t-il, que du seul jeûne (anaśana, Bcar 12.94) pratiqué par Sākyamuni qui ne se nourrit successivement que d'un seul grain de jujube (kola), de sésame (tila) puis de riz (taṇula). Il ne mentionna ni la répression de la pensée ni la rétention de la respiration. Par ailleurs, alors que ces mortifications furent décrites de manière négative et furent rejetées dans les Sūtra

13. Fó suóxíng zàn, 佛所行讃, T. 192, vol. 24, p. 24b12-29. 
et Vinaya des écoles anciennes, tout comme dans le Lalitavistara, le poète cultiva le vieux topos (tarka) brāhmanique de l'ascète émacié rayonnant d'énergie :
« Autant cette ascèse son corps amoindrissait, autant son énergie l'accroissait.
Bien qu'il fût émacié, sa beauté et sa gloire resplendissaient, [et] il procurait de la joie à ceux qui le regardaient, tel de la lune brillante d'automne le croissant [fait s'épanouir à la nuit tombée] les lotus blancs ${ }^{14}$

Le Lalitavistara, biographie du Buddha rédigée par un dévot bouddhiste mahāyāniste, prêcheur de la doctrine (dharmabhāṇaka) dans le nord de l'Inde entre la fin de la seconde moitié du $\mathrm{II}^{\mathrm{e}} \mathrm{s}$. apr. J.-C. et la première moitié du III $^{\mathrm{e}} \mathrm{s}$. apr. J.-C. ${ }^{15}$, fit l'objet d'une traduction chinoise, réalisée par Dharmarakșa, le Sūtra de la

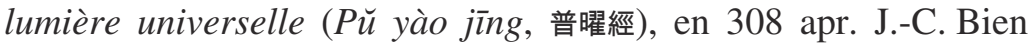
que lacunaire en certains passages, cette dernière garantit l'ancienneté dudit épisode. Y sont attestées les visites à Ārāọa Kālāma et Udraka Rāmaputra (磷頭藍弗 Yutoulanfu' ${ }^{16}$ ) et les pratiques respiratoires (āsphānaka; 出入息, chūrù $\mathrm{Xi}^{17}$ ) ainsi que du jeûne et de ses conséquences. Il est notoire que la répression de la pensée en est absente.

L'ensemble demeure assez concis eu égard à la version sanskrite fixée au début du VIII ${ }^{\mathrm{e}}$ s. apr. J.-C. qui apparaît, de beaucoup, plus développée, bien plus encore parfois que la traduction chinoise que Divākara acheva, en 683 apr. J.-C., sous le titre Sūtra développé de la grande ornementation (Fāngguăng dàzhuāngyán jīng, 方廣大莊嚴經). Il s'ensuit donc que le texte original du Lalitavistara faisait mention de ces six années (六年, liùnián) d'austérités（勤苦行, qínkǔxíng) pratiquées par le Bodhisattva, seul à avoir été capable de réaliser un tel exploit parmi les dieux et les humains (天世人, tiān shìrén). L'auteur mahāyāniste remettait ainsi en cause implicitement les mérites des śravaka et des pratyekabuddha, réservant alors cette

14. dehād apacayas tena tapasā tasya yah kṛtah | sa evopacayo bhūyas tejasāsya kṛto’bhavat || kṛ́so'py akṛ́śakītiśrīr hlādam cakre'nyacakṣuṣām I kumudānām iva śaracchuklapakșāadicandramāḥ II, Bcar 12.97-98.

15. Guillaume Ducoeur, La vie du Buddha. Lalitavistara sūtra ou Sūtra du développement des jeux [du Bodhisattva], II ${ }^{e}-V I I^{e}$ siècle après J.-C., Strasbourg, Presses universitaires de Strasbourg, 2018.

16. T. 186 , vol. 3 , p. 510 b.2.

17. T. 186, vol. 3, p. $511 \mathrm{a} 9$. 
prouesse ascétique qu'aux seuls bodhisattva en voie de devenir dans leur dernière existence terrestre (一生補處菩薩, yīshēng bǔchù púsà) des samyaksambuddha : «Et je me plongerai dans la concentration āsphānaka, dont l'assise est solide comme le diamant, concentration que les pratyekajina ${ }^{18}$ sont incapables de faire voir. ${ }^{19}$. Cette pratique des choses difficiles (dușkaracaryā) est ainsi devenue un passage obligatoire dans la carrière d'un bodhisattva. Une telle conception mahāyānique ne fut certainement pas sans incidence sur la pratique de ceux qui suivaient le bodhisattvayāna.

L'épisode dans sa forme condensée est également conservé dans d'autres biographies partielles, notamment dans la traduction chinoise du Cāryanidānasūtra ou Sūtra sur l'origine de la carrière [du Buddha] (Xiūxíng běnqǔ jīng, 修行本起經), une biographie du Buddha - de sa descente du ciel Tușita à la défaite de Māra -, réalisée en 194 apr. J.-C. par Mahābala (Zhu Dali, 筑大力) et le sogdien Kang Mengxiang (康孟詳). Ne s'étant nourri quotidiennement que d'un seul chènevis et d'un seul grain de riz (一麻一米, yīmá yīmǐ), Śākyamuni fut si émacié (瘦, shòu) qu'il finit par avoir la peau sur les os (皮骨相連, pí gǔ xiàng lián ${ }^{20}$ ). Kang Mengxiang fit aussi allusion à ces six années d'ascétisme dans sa traduction chinoise du Sūtra de l'enseignement du Buddha sur la pratique qui élève $e^{21}$. L'épisode se retrouve sous une forme légèrement plus longue dans le Sütra des causes et effets passés et présents ${ }^{22}$, traduction chinoise d'une vie du Buddha - de sa naissance au don de la Bambouseraie (Jetavana) -, réalisée entre 435 et 443 apr. J.-C. par le bhikșu indien Gunabhadra (Qiunabatuoluo, 求那咙陀羅, 394-468), qui fut originaire du Magadha et qui s'établit en Chine du Sud au temps des Liu Song (劉宋, 420-479). De même, en est-il dans le Sütra rassemblant les actions passées du Buddha ${ }^{23}$ traduit en chinois par le moine gandhārien Jñānagupta (Shenajueduo 闈那崛多) entre 587 et 591. En somme tout un ensemble de biographies qui furent composées

18. Sur l'équivalence entre les termes pratyekabuddha et pratyekajina, voir sarvabuddhabodhisattvāryaśrāvakapratyekabuddhebhyo (Lv 1.1-2) et buddhaśrāvakapratyekajinānām (Lv 20.9²).

19. āsphānakaṃ ca dhyānaṃ dhyāyeyaṃ vajrakalpadṛ̣hasthānam yaṃ dhyānaṃ na samarthāḥ pratyekajināpi darśayitum, Lv 17.24.

20. T. 184 , vol. 3 , p. $469 \mathrm{c} 5$.

21. Fóshuō xīng qüxíng jīng, 佛説興起行經, T. 197, vol. 4, p. $164 \mathrm{~b} 16$.

22. Guōqùxiànzàiyìn guójīng, 過去現在因果經, T. 189, vol. 3,p. 638b26-639a28.

23. Fó běnxíng jí jing, 佛本行集經, T. 190, vol. 3, p. 764c-772a. 
à partir de la seconde moitié du $\mathrm{II}^{\mathrm{e}} \mathrm{s}$. apr. J.-C., date à laquelle apparurent également dans l'art gandhārien des représentations de Sākyamuni émacié.

Dans l'art figuratif, seule l'apparence émaciée de l'ascète des Śākya put faire l'objet d'un effet visuel compréhensible de tous. Il n'était, en effet, guère possible de rendre la répression de la pensée, ni la rétention de la respiration. La représentation squelettique de Śākyamuni se retrouve donc aussi bien sur des bas-reliefs (fig. 1 et 2) que dans la statuaire (fig. 3). Les artistes du Gandhāra optèrent pour figurer cet épisode de la vie du fondateur par la mise en évidence de son corps exténué au terme des six années de jeûne : côtes et veines saillantes, épine dorsale formant une ligne de boules, yeux enfoncés dans les orbites, peau desséchée et collée aux os. Toutes ces représentations ont été exécutées au cours des II ${ }^{\mathrm{e}}$ et III $^{\mathrm{e}}$ siècles apr. J.-C. dans le Nord-Ouest indien sous le règne des rois Kușāna ${ }^{24}$. Cependant, la figuration symbolique de l'épisode est encore plus ancienne, puisqu'elle se retrouve sur le portail (toraṇa) est du grand stūpa de Sāñcī érigé sous le règne des rois Śātavāhana au $\mathrm{I}^{\text {er }}$ s. av. J.-C. Le fait que la jeune Sujātā fut représentée en train d'offrir un bol de nourriture au futur Buddha, symbolisé par le parasol (chattra), insigne du pouvoir royal (fig. 4), atteste bien que celui-ci abandonna la pratique du jeûne et qu'il décida de s'alimenter de nouveau afin de recouvrer ses forces et d'atteindre l'éveil. Ceci induit que le rejet de l'ascétisme rigoriste remonte au moins avant le $\mathrm{I}^{\mathrm{er}} \mathrm{s}$. av. J.-C. et qu'il fut revendiqué par les écoles anciennes pré-mahāyāniques comme en témoignent les Sutta.

\section{L'ÉPISODE ET SA STRUCTURE}

Nous nous intéresserons donc à la version longue telle qu'elle se retrouve conservée dans les écrits des écoles anciennes à savoir Mahāsaccakasutta et Mahāvastu. Leur structure commune peut être réduite aux éléments narratifs suivants. Dans le Sutta, la scène se déroule au Magadha à Uruvela près d'un bosquet et d'une rivière et non loin d'un village rendant les tournées d'aumône possibles. C'est

24. Voir en dernier lieu Osmund Bopearachchi, When West met East: Gandhāran Art Revisited, Manohar Publishers, New Delhi, 2019. 
ici que vinrent à la pensée de Śākyamuni trois analogies fondées sur l'attachement aux désirs et ses conséquences sur l'incapacité à obtenir l'éveil. Dans le Mahāvastu, la scène se passe sur le mont Gayāśîișa ${ }^{25}$ et l'ascète des Śākya se rend peu après à Uruvilvā. C'est donc dans ce cadre champêtre, au calme, assis non loin des bords d'une rivière, nommée Nairañjanā dans le Mahāvastu, qu'il décida de s'appliquer à plusieurs sortes de rétention.

La première est basée sur la pratique de la répression de la pensée par la pensée consciente (cetasā cittaṃ) : «Il faut que, ayant serré les dents, ayant pressé mon palais avec ma langue, je réprime fermement ma pensée à l'aide de ma pensée consciente, que je la comprime, que je l'écrase complètement $»^{26}$. Dans le Mahāvastu, l'opération consiste à subjuguer et la pensée et le corps : «Alors, ô religieux-mendiants, je réprimais et comprimais mon corps et ma pensée par la pensée consciente $»^{27}$. En résulta une sudation au niveau des aisselles, dans le Sutta, au niveau des aisselles, de la face et du front (mukhato lalātạato) amenant un flot de gouttes de sueur à tomber à même le sol pour s'évaporer immédiatement, dans le Mahāvastu. Dans le contexte du Sutta, le Buddha expliqua à Saccaka que son corps n'était alors nullement apaisé. Cette répression de la pensée n'est pas présente dans tous les textes relatifs à la pratique des austérités. En l'état des sources, ceci montre que seule l'école du theravāda et, dans une moindre mesure, celle des Lokottaravādin ont développé cette mortification basée sur l'arrêt de l'activité mentale. Cependant, il convient de rappeler que, dans les Sutta des Theravādin et des Sarvastivādin ainsi que dans les Vinaya des Dharmaguptaka et des Mahāsāṃghika, Śākyamuni, qui suivit l'enseignement d'Ārāḍa Kālāma et d'Udraka Rāmaputra, avait déjà reconnu que l'état sans

25. Dans le Lalitavistara, la scène se déroule également sur le mont Gayāšîiș̣a (gayāśīișe parvate, Lv éd. Vaidya 17.181). Néanmoins, le texte original ne devait pas faire mention du nom de la montagne puisque Dharmarakșa signale simplement qu'il «erra en des lieux montagneux » (遊在山間, yóu zài shān jiān, T. 186, p. 510a29). Ce fut assurément le relecteur du ve s. apr. J.-C. qui précisa l'oronyme selon la tradition mahāsāṃghika. Ceci est confirmé par la traduction de Divākara (伽耶山, Jiāyé shān, T. 187, p. 580c14).

26. yannūnāham dante' bhidantamādhāya jivhāya tāluṃ āhacca cetasā cittam abhiniggaṇheyyaṃ abhinippīleyyaṃ abhisantāpeyyanti, PTS, MN, vol. 1, sutta 36, p. 242.

27. sa khalv aham bhikṣava idam eva kāyam cetasā evaṃ ceta abhinigṇhṇe abhinipīẹe, Mhv 2.124. 
perception ni absence de perception (naivasaṃjñānāsaṃjñāyatana) ne menait ni à la connaissance discernante, ni à l'éveil.

La deuxième rétention concerne la respiration. Le Mahāsaccakasutta et le Mahāvastu ont en commun un vocable technique identique et attestent que les auteurs ont dû puiser à la même source : «Il faut maintenant que je me plonge dans la concentration de l'arrêt respiratoire » (yan nūnāhaṃ appāṇakạ̣ jhānaṃ jhāyeyyanti ${ }^{28}$ / yạ̣ nūnāhaṃ āsphānakaṃ dhyāyeyaṃ ${ }^{29}$ ). Il s'agit pour Śākyamuni de procéder à l'interruption ou au blocage (uparudh-) de tout mouvement d'inspiration (praśvāsa) et d'expiration (āśvāsa). Le terme technique a-prāna-ka atteste l'idée même de suspension totale de la respiration. Cette pratique est répétée à des degrés de plus en plus élevés par l'ascète des Śākya à cinq reprises dans le Sutta, et à seulement deux dans le Mahāvastu (bhūyasyā mātrayā). Les conséquences en furent des bruits violents dus aux souffles s'échappant de ses oreilles, puis, une fois les oreilles bouchées, à ceux soulevant le dessus de sa tête. Le Sutta place ici un passage absent du Mahāvastu, présent cependant dans le Lalitavistara. Plusieurs divinités s'interrogèrent sur l'état de santé de Sāayamuni et avancèrent qu'il était soit mort, soit en train de mourir. D'autres affirmèrent au contraire qu'il suivait la pratique ascétique des arhant et qu'il en était ainsi devenu un ${ }^{30}$.

Ces deux premières rétentions, de la pensée et de la respiration, sont propres aux pratiques yogiques et se trouvent explicitement mentionnées au moins dès le $\mathrm{II}^{\mathrm{e}}$ s. av. J.-C. dans la Bhāgavad Gìtā. La fermeture de tous les orifices et l'interruption complète de la respiration dans le sommet du crâne renvoient à la pratique de la fixation de la pensée : «En fermant tous les orifices, en bloquant en soi la pensée, en retenant dans la tête sa respiration, on réalise la fixation de la concentration mentale » (sarvadvārāṇi saṃyamya mano hṛdi nirudhya ca mūrdhny ādhāyātmanạ prāṇam āsthito yogadhāraṇām ${ }^{31}$, BhG 8.12).

28. PTS, MN, vol. 1, sutta 36, p. 243.

29. Mhv 2.124.

30. araham samaṇo gotamo vihārotveveso arahato evarūpo hotī, PTS, MN, vol. 1, sutta 36, p. 245. Cf. api tudhyānavihāra eșo 'rhatām evaṃ vidha iti, Lv 17.184.

31. La fixation du mental ou dhārañā est l'un des huit auxiliaires du yoga selon Patañjali. Cette fixation est obtenue par le travail de protraction de la respiration (prāṇāyāma) et plus particulièrement par l'interruption (viccheda) complète de cette dernière. YS 2.49 et 53. 
La troisième rétention porte sur la maitrise d'absorption de nourriture et la pratique graduelle du jeûne. Dans le Sutta, les divinités l'en dissuadèrent et lui proposèrent même de le nourrir par les pores de sa peau grâce à une substance nutritive divine. Ce qu'il refusa. Dans le Mahāvastu, tout comme dans le Lalitavistara, ce passage se trouve à la fin du jeûne complet avant la reprise d'une alimentation plus équilibrée, notamment offerte par Sujātā. Dans le Sutta, il diminua sa nourriture composée exclusivement de soupes de légumes. Dans le Mahāvastu, il ne se nourrit plus respectivement que d'un seul jujube, un grain de riz, puis une graine de sésame pour ne plus se nourrir du tout. Dans les deux cas, ce jeûne graduel l'amena à l'affaiblissement complet de son corps. Les descriptions de son état anorexique sont plus longuement développées dans le Mahāvastu et le Lalitavistara que dans le Sutta des Theravādin.

Le constat qu'il fit fut amer. Cette pratique extrêmement douloureuse suivie par les śramanes et les brāhmanes ne lui permit pas d'atteindre la noble vision de la connaissance (ariyañāṇadassana ${ }^{32}$ / āryam jnānadarśanaṃ ${ }^{33}$ ). Dès lors, Śākyamuni se demanda si une autre voie ne mènerait pas à l'éveil (siyā nu kho añño maggo bodhāyā / nāyạ̣ mārgaṃ bodhāya). Se rappelant son expérience du premier stade de concentration (paṭhamạ̣ jhānam / prathamạ̣ dhyānam) lorsque encore jeune, il s'était assis à l'ombre d'un jambosier dans le jardin de son père, et dans lequel il atteignit un état de bonheur (sukha), séparé des désirs et des choses mauvaises, il eut la conviction que là résidait la voie de l'éveil (eso va maggo bodhāyāti / eva mārgo bodhāye). Après avoir saisi qu'il ne servait à rien d'avoir peur de ce bonheur puis après avoir repris des forces grâce à la nourriture offerte par Sujātā, il alla s'asseoir sous un arbre et, une fois passé par les quatre stades de la concentration (dhyāna), l'ascète des Śākya atteignit l'éveil, c'est-à-dire la vision claire du mécanisme du saṃsāra et les moyens de l'enrayer exprimée dans les quatre nobles vérités. 


\section{LA CRITIQUe de LA PRATIQUe des AUSTÉrités}

Le fondement de la doctrine bouddhique a grandement conditionné la structure compositionnelle de la vie du Buddha du temps présent et plus largement de tous les Buddha des temps passés. Les biographies traditionnelles témoignent de ce travail basé sur l'exposition de la doctrine de la voie moyenne (madhyamā pratipad), professée à Vārānasī et excluant les deux modes de vie extrêmes : celui des désirs (kāma) propre au monde des gṛhapati ou maitres de maison, et celui de l'ascétisme rigoriste menant à l'épuisement du corps (ātmakāyaklama, Lv 26.303). De ce fait, la période pré-bodhique montre comment Siddhārtha Gautama expérimenta ces deux domaines d'action, l'un durant sa jeunesse princière - vie mondaine emplie de jouissances, sources de douleurs (cycle de Kapilavastu) -, l'autre durant six années de mortifications qui n'engendrèrent pour finir que tourments physiques et mentaux (cycle du Magadha). C'est donc à partir de cette doctrine de la voie moyenne que la vie du fondateur fut construite. Comme l'affirmait à juste titre A. Bareau, «l'ordre dans lequel ont été imaginés les divers éléments de cette histoire de la pratique des austérités par le Bodhisattva, y compris les allusions qui y sont faites ici et là, est l'inverse de celui dans lequel ils apparaissent dans la biographie, l'ordre inverse de la chronologie de celle-ci $»^{34}$. L'épisode des mortifications fut donc conçu à partir des fondements de la doctrine et a posteriori. Il ne s'agit aucunement d'un quelconque souvenir historique de la vie du fondateur.

La première voie extrême, celle du kāma ou plaisir des sens, relève du contact entre les organes des sens et les objets des organes des sens qui produit des sensations agréables, désagréables ou ni agréables, ni désagréables, engendrant à leur tour attachement et désir d'en jouir ou de ne pas en jouir à nouveau, mais toujours désir (tṛ̣ṇāa). C'est tout autant le monde des maîtres de maison que celui de certains śramanes qui s'accordaient toute jouissance, notamment avec des femmes. Dans l'Alagaddūpamasutta, le bhikșu Arițtha, par exemple, avançait que les relations sexuelles ne faisaient aucun obstacle (antara) à la vie religieuse, ce à quoi le Buddha lui rétorqua qu'il ne pouvait y avoir de désir (kāma)

34. André Bareau, Recherches sur la biographie du Buddha..., p. 178. 
sans conscience du désir (kāmasañ̃̃āa) ${ }^{35}$. De même, dans les Vinaya, la première raison d'expulsion (pārājika) du saṃgha pour un bhikșu est due à toute relation sexuelle consciente. L'histoire de Sudinna ${ }^{36}$ relate comment ce jeune de bonne famille, après avoir quitté son foyer pour la vie de religieux-mendiant et avoir atteint l'état d'arhant, retourna visiter sa famille et comment ses parents, désolés de ne pas avoir de descendance, demandèrent à son ancienne femme, leur bru, de leur en donner une. Les règles disciplinaires n'indiquant aucune interdiction dans ce cas précis, Sudinna se rendit avec son ancienne femme dans la forêt pour s'y unir et lui offrir ainsi cette descendance tant attendue. Or, l'auteur du Vinaya poursuit en affirmant qu'étant pris de remords (vippatịsāro), Sudinna fut accablé de souffrances (dukkhī) et son apparence physique changea. Émacié (kiso), desséché (lūkho), son teint devint vilain et blafard (dubbaṇno uppaṇụuppạ̣ukajāto), ses veines saillantes (dhamanisanthatagatto). En définitive, l'état physique et mental dans lequel se retrouve tout ascète qui pratique les mortifications à l'égal de Śākyamuni après ses six années d'austérités. L'aboutissement négatif de la voie du kāma fut donc considéré par l'école theravāda comme la contrepartie exacte de celle de l'ascétisme rigoriste.

La seconde, les pratiques difficiles (dușkaracaryā), à savoir l'arrêt de la pensée, la rétention complète du souffle et le jeûne, vise à la maîtrise complète des organes des sens et donc à couper tout contact entre ces derniers et les objets des organes des sens afin d'interrompre toute sensation, et donc tout désir. Option considérée alors comme dangereuse car engendrant un flot continuel de tourments et de souffrances (duhkha), ce à quoi cherche justement à échapper l'adepte de la doctrine bouddhique. Selon les écoles anciennes, la voie que le Buddha révéla à Vārānasī fut donc moyenne ou médiane car basée sur huit pratiques correctes ou « chemin à huit auxiliaires » (așțāngamārga), excluant tout excès préjudiciable à l'obtention de la cessation du désir. En somme, une pratique d'observation consciente des mécanismes à l'origine de la production des désirs physiologiques et mentaux et une orientation positive de l'agir, basée sur le développement des sensations de

35. PTS, MN, vol. 1, sutta 22, p. 133.

36. PTS, Vinaya, vol. 3.1., p. 11-21. 
bonheur et de joie détachées des désirs et des choses mauvaises, pour s'en affranchir.

Ainsi, en le dépeignant tourmenté par les mortifications qu'il s'infligea, arrivé au seuil de la mort, l'auteur ou les auteurs cherchèrent à montrer que leur fondateur avait expérimenté l'inanité de cet ascétisme rigoriste qu'il avait fini par abandonner. Pour ces auteurs bouddhistes, de telles pratiques étaient à rejeter. Néanmoins, il convient de s'interroger sur l'histoire de ce rejet qui ne visait certainement pas que les seuls śramanes et brāhmanes non-bouddhistes.

\section{Les śramanes et les brāhmanes}

Si nous nous en tenons au contenu des deux textes, theravāda et mahāsāṃghika, il ressort que ces pratiques mortificatoires étaient imputables aux seuls śramanes et brāhmanes (samaṇā vā brāhmaṇā / śramaṇā vā brāhmaṇā). L'arrêt de l'activité mentale ou le contrôle de la pensée, la rétention de la respiration ou encore le jeûne sont autant de techniques ascétiques pré-bouddhiques dont nous pouvons trouver trace dès la période des plus anciennes Upanișad $^{37}$ poursuivant le savoir ritualiste explicatif des Brāhmaṇa et les pratiques ascétiques solitaires des Áranyaka. Quant aux jeûnes, ils relevaient des mortifications ardentes ou tapas. Selon les Dharmasūtra et les Dharmaśāstra datant entre le $\mathrm{V}^{\mathrm{e}}$ et le $\mathrm{II}^{\mathrm{e}} \mathrm{s}$. av. J.-C., ils étaient de deux sortes. Le cāndrāyaṇa ou jeûne suivant le cours de la lune, cité en Lalitavistara 17.183, demandait de réduire puis d'augmenter le nombre de bali ou boulettes en fonction des phases lunaires. Le jeûne était complet lors de la nuit noire sans lune. Le sāṃtapana ou kṛcchrasāṃtapana (douleur et brûlure) exigeait d'absorber, sur une semaine, six substances, à savoir urine de vache, bouse de vache,

37. En Brhadāranyakopanișad 1.5.21-23, appartenant à l'école du Yajur veda - le savoir des formules sacrificatoires propre à l'adhvaryu ou officiant chargé des manipulations rituelles - une inclusion sur le rôle médiateur du prāṇa ou souffle atteste de l'assimilation par cette école védique de techniques respiratoires spécifiques. La mort (mṛtyu), personnification du mal (pāpman) par excellence, n'a aucune emprise ni sur le souffle vital des humains, ni sur le souffle cosmique qu'est le dieu Vāyu. Ainsi, l'auteur préconise une pratique unique (tasmād ekam eva vratam caret), celle pour laquelle il convient d'expirer et d'inspirer afin d'échapper à l'emprise de la mort. En pratiquant jusqu'au bout ce travail respiratoire, on conquiert (jayati), affirme-t-il, l'union (sāyujyamin) à la divinité et une place en sa demeure (salokatāị). 
lait, yaourt, beurre clarifié et infusion d'herbe kuśa. Le septième jour, l'ascète réalisait un jeûne complet ${ }^{38}$.

Le Sutta bouddhique, quant à lui, énumère comme nourriture prise par Śākyamuni des soupes (yūsa, skt yūṣa) à base de fève (mugga, skt mudga), de vesce (kulattha), de pois (kalāya) et de millet (harenuka) alors que le Mahāvastu cite le jujube (kola), le grain de riz (taṇ̣ula) et la graine de sésame (tila). Il apparaît donc que la tradition au sujet de cet épisode du jeûne demeurait flottante. Au temps du Buddha, les brāhmanes érémitiques ou āraṇyaka, selon Baudhāyanadharmaśāstra 3.3.2 ( $\mathrm{V}^{\mathrm{e}}-\mathrm{IV}^{\mathrm{e}} \mathrm{s}$. av. J.-C.), faisaient cuire leur alimentation (pacamānaka) ou non (apacamānaka). Parmi eux existaient ceux qui se nourrissaient de graines (vaitușika) et de fruits (phalabhakșa). Contemporain du Buddha, Hérodote (env. 485-430 av. J.-C.) mentionne, dans son Enquête (3.100), de tels ascètes qui vivaient dans la haute vallée indusienne et qui ne se nourrissaient que de grains de riz bouillis. Ces différentes mortifications pratiquées par les śramanes et brāhmanes furent donc rejetées par les Theravādin et les Mahāsāṃghika.

Les sources bouddhiques ne manquent pas de définitions sur le statut du vrai renonçant. Dans le Dhammapada ou Strophes sur la doctrine, texte gnomique et didactique commun aux écoles sthaviravāda et mahāsāṃghika, n'est plus considéré comme brāhmane véritable, le brāhmane issu du varṇa héréditaire brāhmanique. Cette remise en cause du statut social du brāhmane est déjà ancienne et remonte à la période védique comme l'atteste la Maitrāyāṇisaṃhitā (4.8.1). S'est imposé dans le paysage religieux de l'Inde ancienne, divisé entre brāhmanes et śramanes - division reconnue par la chancellerie royale maurya elle-même comme en témoignent les édits aśokéens -, un topos, celui de l'ascète forestier émacié : «Une personne vêtue de haillons ramassés dans la poussière, émaciée, aux veines saillantes, qui médite, solitaire, dans la forêt, c'est lui que j'appelle brāhmane. Mais je n'appelle pas brāhmane celui qui l'est de naissance par sa mère. $»^{39}$.

38. Gautamadharmasūtra 27.1-18 et 26.1-25; Apastambadharmasūtra 1.27.1-8 ; Baudhāyanadharmaśāstra 3.8.1-31 et 2.2.37-45 ; Vāsișthadharmaśāstra 23.44-47, 23.42-43 et 24.1-5. Cf. Mānavadharmaśästra 11.212, 214 et 218.

39. paṃsukūladharaṃ jantum kisạ̣ dhamanisanthatạ̣ ekạ̣ vanasmiṃ jhāyantạ̣ tam ahaṃ brūmi brāhmaṇaṃ na cāhạ̣ brāhmaṇạ̣ brūmi yonijạ̣ mattisambhavam, DhP 395-396a. 
Pourtant, un tel aspect ne suffit nullement pour l'auteur bouddhiste à faire de ce brāhmane non-héréditaire un brāhmane véritable. Car les pratiques ascétiques peuvent elles-mêmes n'aboutir qu'à la fabrique d'un nouveau statut identitaire apparent à l'égal de l'hérédité sociale brāhmanique dénoncée. Le bhikṣu, par sa tenue vestimentaire et sa conduite, propre au chemin à huit auxiliaires, se démarque ainsi du soi-disant ascète toujours prisonnier de ses propres désirs : «Ni la nudité, ni le chignon, ni la malpropreté, ni le jeûne, ni coucher à même le sol, ni [se couvrir] de poussière et de boue, ni se tenir accroupi sur les talons, ne peut purifier le mortel qui n'a pas dépassé ses désirs. Quoique paré [d'une belle étoffe], il se conduit avec calme, apaisé [de toute passion], dompté, se maîtrisant, chaste et a renoncé à fustiger tous les êtres : c'est lui le brāhmane, le śramane, le bhikṣu. $»^{40}$.

Les śramanes et les brāhmanes qui souhaitaient entrer dans le samgha avaient donc pour obligation d'abandonner leur ancien mode de vie, parfois les plus extravagants, et leurs pratiques corporelles fussent-elles basées sur l'arrêt de l'activité mentale, la rétention du souffle ou le jeûne. Dans le Kukkuravatikasutta ${ }^{41}$, sont donc énoncées les conditions d'acceptation de ces śramanes issus d'une autre secte qui menaient une vie semblable à celle d'une vache (govatiko), tel Punnạ, ou d'un chien (kukkuravatiko), tel Seniya. Toute personne qui avait appartenu auparavant à une autre secte (añnatitthiyapubbā) et qui désirait recevoir l'ordination mineure (pabbajjā) puis l'ordination majeure (upasampadā) dans la doctrine et la discipline (dhammavinaye) devait vivre en probation durant quatre mois. À la fin de ces quatre mois, si les bhikṣu étaient satisfaits de lui, ils lui conféraient l'ordination mineure puis l'ordination majeure de l'état de bhikṣu ${ }^{42}$. Ainsi, après quatre mois, Seniya, qui avait abandonné son ancien mode de vie ascétique, fut-il accepté par le saṃgha et obtint sa pleine ordination après quatre années de vie en probation, avant d'atteindre le statut d'arhant. Mais il serait erroné de penser que l'épisode des mortifications dans lequel la description de Śākyamuni

40. na naggacariyā na jațā na paṃkā nānāsakā thaṇ̣ilasāyikā vā rajo va jallạ̣ ukkuṭikappadhānaṃ sodhenti maccaṃ avitiṇṇakạ̣khạ̣ alaṃkato ce pi samạ̣ careyya santo danto niyato brahmacārī sabbesu bhūtesu nidhāya daṇ̦̣ạ so brāhmaṇo so samaṇo sa bhikkhu, DhP 141-142.

41. PTS, MN, vol. 1, sutta 57, p. 387-392.

42. PTS, MN, vol. 1, sutta 57, p. 391. 
exténué reprend et développe ce topos de l'ascète forestier solitaire, ne s'adresse qu'aux seuls śramanes et brāhmanes. Car il s'adresse avant tout et surtout aux bhikșu bouddhistes eux-mêmes.

\section{Deux voies bouddhiques opposées : tapas et prajñā}

Il est indéniable que l'épisode du premier enseignement de la doctrine à Vārāṇasī, que partagent les écoles sthaviravāda et mahāsāṃghika puis, en leur temps, les mahāyānistes, s'ouvre non pas sur une exposition de la doctrine telle que cette dernière apparaît à travers les quatre nobles vérités ou bien la voie à huit auxiliaires ou aides (añga), mais bel et bien par une règle de discipline propre aux Vinaya. La voie moyenne (madhyamā pratipad) à laquelle doivent être rattachés les épisodes et de la vie princière et de la pratique des austérités (duṣkaracaryā), s'adresse donc avant tout aux bhikṣu, aux membres de la communauté bouddhique. Par conséquent, si la madhyamā pratipad apparaît comme le Vinaya par excellence, c'est bel et bien parce que le samgha compta parmi lui, d'une part, une masse de bhikșu convertis qui avaient auparavant suivi d'autres doctrines et pratiques d'écoles śramaniques et brāhmaniques fort hétérogènes et, d'autre part, un ensemble de bhikșu qui, bien qu'ayant reçu l'ordination, n'étaient pas forcément d'accord entre eux quant aux moyens corporels et mentaux à mettre en œuvre pour atteindre l'extinction (nirvāna), voire l'éveil (bodhi).

À ceci s'ajoutent deux modes de vie distincts qui ont grandement favorisé des approches différentes pour réaliser le dharma bouddhique. Le premier relève de l'érémitisme en des lieux inhabités (āraṇyaka), le second du cénobitisme (saṃghārāma). Les premiers vivaient en plein air à l'abri des arbres, se vêtaient de haillons, mendiaient leur nourriture, ne pouvaient prendre comme remède médical que la seule urine de vache et pratiquaient l'ascétisme (tapas) et la diète (àjīiva). Ceci n'est pas sans faire écho à la vie menée par Śākyamuni avant son éveil. Dans la tradition bouddhique, l'un de leurs représentants est assurément Devadatta qui résidait, entouré de bhikșu et bhikșuṇī āraṇyaka, sur le mont Gayāśīișa. Si la dissidence (samghabheda) entre Devadatta ${ }^{43}$ et le Buddha, due à

43. André Bareau, «Les agissements de Devadatta selon les chapitres relatifs au schisme dans les divers Vinayapitaka », Bulletin de l'École française d'ExtrêmeOrient, Tome 78, 1991, p. 87-132. 
l'observance de cinq règles disciplinaires rigoristes (dhutaguṇa ${ }^{44}$ ), est historique, ce qui semble l'avoir été au témoignage de Faxian qui rencontra encore des adeptes de l'école de Devadatta (調達, Diaoda) en Inde au début du $\mathrm{V}^{\mathrm{e}} \mathrm{s}$. apr. J.-C.4. ${ }^{45}$ il s'avérerait alors que certaines écoles anciennes ont assimilé le lieu même où vécurent ces bhikșu āranyaka pour en faire l'emplacement même où Śākyamuni resta six années à pratiquer de vaines mortifications. Les seconds, plus sédentaires, vivaient dans des lieux d'assemblée implantés près des villes et bénéficiaient alors des largesses des dévots (upāsaka), tant en textile et en nourriture qu'en médicaments et pouvaient se voir également invités à dîner chez ces derniers afin de leur transmettre le dharma. Dans le Gulissānisutta ${ }^{46}$, l'éminent disciple Śaripūtra, spécialiste de la discipline et chef des auditeurs (aggasāvaka), met en garde les bhikṣu forestiers (āraññako bhikkhu) qui seraient irrespectueux (agāravo) envers les bhikșu vivant une vie moins austère dans les saṃghārāma, car leur irrévérence amènerait leurs confrères sédentaires à demander ce que ces vénérables forestiers ont gagné à demeurer solitaires dans les bois (ekassāraññe) en faisant ce qu'ils voulaient puisqu'ils sont injurieux envers eux. Ces deux modes de vie durent coexister assez tôt dans l'histoire du bouddhisme, probablement déjà du vivant du fondateur, et se retrouvèrent plus fortement en tension dès lors que des structures monastiques se développèrent et s'organisèrent durablement.

De cette dichotomie communautaire en résulta certainement le pratyekabuddhayāna ou véhicule des éveillés-pour-soi ${ }^{47}$ en parallèle du śrāvakayāna ou véhicule des auditeurs. Les sources textuelles des écoles bouddhiques anciennes montrent qu'elles

44. Jean Dantinne, Les qualités de l'ascète (dhutaguna) : étude sémantique et doctrinale, Bruxelles, Thanh-Long, 1991.

45. Gāosēng Făxiăn zhuàn, 高僧法顯傳, T. 2085, vol. 51, p. 861a12. Cf. le commentaire de Yijing, 義淨 (635-713) sur les règles disciplinaires des adeptes de Devadatta (天授, Tianshou), T. 1453, vol. 24, p. 495c14.

46. PTS, MN, vol. 1 , sutta 69 , p. 469-473.

47. Pour Kenneth Roy Norman, le terme pratyekabuddha (pāli : paccekabuddha) serait l'aboutissement de l' appropriation par le bouddhisme et le jaïnisme du concept śramanique de prayayabuddha ou éveillé-par-cause [extérieure] en opposition à leur fondateur respectif regardé comme éveillé-sans-cause [extérieure], c'està-dire par soi-même. Mais une telle interprétation présuppose l'existence d'une antinomie bouddhique et jaïna sans laquelle prayayabuddha n'aurait plus alors de sens. K. R. Norman, "The Pratyeka-Buddha in Buddhism and Jainism », in Philip Denwood and Alexander Piatigorsky (eds.), Buddhist Studies (Ancient and Modern), London, Curzon Press, 1983, p. 92-106. 
ont cherché à donner une place au bhikșu āranyaka au sein de leur propre organisation communautaire sédentarisée. Or, ce courant ascétique bouddhique s'origine assurément dans le mode de vie prébouddhique de certains śramaṇa solitaires qui avait pour finalité d'atteindre l'éveil par eux-mêmes à l'aide d'un travail ascétique rigoriste et non en fonction de l'enseignement d'un maître autoproclamé éveillé et confessé tel par ses auditeurs. C'est ce qui distingue selon les écoles du sthaviravāda les pratyekabuddha ${ }^{48}$ des samyaksambuddha, les premiers n'ayant pas la faculté de transmettre les quatre nobles vérités à autrui, à la différence des seconds. Dans les Sutta et le Lalitavistara, nous avons vu que la pratique des austérités de Śākyamuni était considérée comme relevant du mode de vie des arhant, c'est-à-dire de ceux d'entre les bhikṣu qui menaient encore une vie à l'égal des premiers disciples du Buddha, des bhikṣu āranyyaka et des pratyekabuddha.

Plus encore, s'opposent, dans le saṃgha, les jhāyī bhikkhū, c'està-dire les bhikșu passant leur temps à la pratique de la concentration et les dhammayogā bhikkhū, les bhikṣu qui s'attellent à la seule observance de la doctrine. Le Dhammikavagga ${ }^{49}$ atteste que ces deux types de bhikṣu se blâmaient (apasādenti) mutuellement. Les premiers prétendaient toucher avec leur corps (kāyena phusitvā) le plan immortel (amatạ̣ dhātuṃ), c'est-à-dire le nirvāṇa ${ }^{50}$. Les seconds affirmaient voir par leur pénétrante connaissance (paññāya ativijjha) la profonde réalité (gambhīrạ̣ atthapadaṃ) ${ }^{51}$.

Ces différentes tensions sont tout à fait palpables dans le traité apologétique du Milindapañha (II ${ }^{\mathrm{e}} \mathrm{s}$. av. J.-C.) tel qu'il est conservé chez les Theravādin. Si l'habitat dans des structures monastiques et la discussion des sūtra étaient décriés par les tenants de l'érémitisme, les écoles anciennes sédentarisées n'hésitèrent pas à défendre et leur mode de vie et leur voie spéculative et intellectuelle, cette dernière menant tout autant au nirvāṇa et considérée elle-même comme incomposée :

48. Sur le pratyekabuddhayāna voir Ria Kloppenborg, The Paccekabuddha: A Buddhist Ascetic, Kandy, Buddhist Publication Society, 1983 ; Bhikkhu Anālayo, « Paccekabuddhas in the Isigili-sutta and its Ekottarika-āgama Parallel », Canadian Journal of Buddhist Studies, 2010, vol. 6, p. 5-36 ; « Pratyekabuddhas in the Ekottarikaàgama », Journal of the Oxford Centre for Buddhist Studies, 2015, vol. 8, p. 10-27.

49. PTS, A[niguttara] N[ikāya], vol. 3, vagga 46, p. 344-374.

50. PTS, AN, vol. 3 , vagga 46, p. 356.

51. PTS, AN, vol. 3, vagga 46, p. 356. 
«L'enseignement et la discussion des textes, l'entretien des bâtiments du monastère, le don et le culte sont d'une grande utilité, quelles que soient les tâches à accomplir. [...] Ô roi, si chacun était tout pur de naissance, un instructeur ne servirait à rien. Bien au contraire, apprendre les textes sert à quelque chose - le thera Sāriputta luimême, qui avait accumulé des racines de bien durant d'innombrables, d'incalculables ères cosmiques, et avait atteint la cime de la sagesse pénétrante (paññāya), ne put couper court aux infections morales en se dispensant d'apprendre les textes; les apprendre est donc d'une grande utilité, tout comme leur enseignement; enseignement et discussion (uddesa-paripucchā) sont donc, eux aussi, non-dispersion (nippapañcā), et incomposés (asañkhatā). » ${ }^{52}$

L'épisode de Sāanyamuni eut donc pour fonction de mettre en garde les ascètes bouddhistes les plus rigoristes, ceux que nous pourrions classer parmi la catégorie wébérienne des « virtuoses » de l'ascétisme dans les voies de salut. Comme le souligne l'historien des religions Jean-Marie Husser, «du fait de leur caractère élitiste, du fait aussi qu'elles concernent des individus qui se mettent en marge de la société, ces voies et ces pratiques ascétiques, volontiers qualifiées de "spirituelles" ou de "mystiques" sont plus ou moins bien intégrées aux systèmes religieux dont elles émanent et se trouvent parfois en tension avec eux $»^{53}$.

L'auteur du Milindapañha défendit ainsi le fondateur face aux accusations dont il était l'objet en dehors du sampha et plus certainement à l'intérieur. Il était notamment reproché au Buddha tout autant de manger à sa faim que de mener une vie peu austère à la différence de certains de ses élèves :

«Certains de ses disciples passaient le jour et la nuit debout, immobiles, ou à marcher de long en large [tout en méditant], alors que le Bienheureux se permettait en outre de s'asseoir et de se coucher ; certains autres ne prenaient qu'un seul repas par jour, et n'eussent pas dérogé à cette pratique, fût-ce au péril de leur vie, tandis que le Bienheureux en prenait deux, ou même trois ${ }^{54}$ : sur ces points, ces moines allaient plus loin que lui. On raconte ainsi

52. Entretiens de Milinda et Nāgasena, traduit du pâli, présenté et annoté par Édith Nolot, Paris, Gallimard, 1995, p. 210-211. PTS, Milindapañha, p. 264.

53. Jean-Marie Husser, Introduction à l'histoire des religions, Paris, Ellipses, 2017, p. 309.

54. Au paragraphe précédent, alors qu'il en vient à répondre aux accusations sur les propos tenus par le Buddha qui avait affirmé à Udayin qu'il lui arrivait de manger un plein bol et même plus, l'auteur alla jusqu'à accuser Devadatta de ne pas avoir contrôler son appétit. PTS, Milindapañha, p. 214. 
beaucoup de choses quant à telle ou telle pratique observée par tel d'entre eux. $»^{55}$

Accusation à laquelle l'auteur rétorqua qu' « en ce qui concerne le Bienheureux, il était insurpassable quant à la moralité (sīlena), à la concentration (samādhinā), à la sagesse pénétrante (paññāya). $»^{56}$ Tout un ensemble de domaines de son champ d'action (buddhavisaye) qui ne relevait pas directement de la nécessité de mener une vie d'austérité, mais qui demandait de pratiquer l'octuple sentier et d'exercer la prajñā ou connaissance discernante. Si, dans le samgha, se transmettaient de telles interrogations sur les capacités d'ascétisme limitées du fondateur, l'épisode même de ses années d'austérités ne manquait pas de soulever des contestations. L'auteur du Milindapañha contrecarra l'idée que, bien que le jeûne et les austérités (āhārapariggaho dukkarakārikā) eussent fait partie de la voie (maggo, paṭipadā) pour obtenir l'éveil, Śākyamuni les abandonna, en avançant que ce fut uniquement son excès de zèle (ativiriyaṃ) ascétique qui l'entraîna vers la dénutrition et l'incapacité à atteindre l'omniscience (sabbaññutam $)^{57}$. Quant à savoir si tous les bodhisattva devaient passer par ces six années (chahi vassehi) d'austérités pour atteindre la connaissance et l'éveil, il affirma que seul Gotama passa par cette pratique ardue qui eut pour finalité d'achever son temps de la maturation de la connaissance et de l'éveil (paripakkaṃ bodhiñāṇaṃ) ${ }^{58}$. Ceci montre assez que cet épisode de la vie du fondateur avait été reçu et compris différemment et que les bhikṣu des écoles anciennes avaient essayé d'en justifier la pertinence dans l'économie de la biographie de leur fondateur ${ }^{59}$ en un temps où la vie monastique s'était considérablement éloignée du mode de vie des bhikṣu âranyaka.

De fait, la difficulté de saisir au mieux la place de ces virtuoses bouddhistes du tapas et de l'āryaṇakisme réside dans le fait que les sources textuelles conservées émanent toutes des milieux

55. Entretiens de Milinda..., p. 177-178. PTS, Milindapañha, p. 216.

56. Entretiens de Milinda..., p. 178.

57. PTS, Milindapañha, p. 245.

58. PTS, Milindapañha, p. 287.

59. L'auteur du Pubbakammapilotikabuddhāpadāna expliqua ces six années d'austérités et de souffrances comme le fruit des actes passés du Buddha, notamment lorsque, né sous l'apparence du jeune brāhmane Jotipāla, il insulta le Buddha Kassapa (Kāśyapa). PTS, Apadāna, vol. 1, therāpadāna 39.387.1-33, p. 299-301. 
cénobitiques, de ces saṃghārāma, parfois richement pourvus, dans lesquels les bhikșu spécialistes du dharma avaient tout loisir de composer et d'écrire sur le dharma même. En fait, nous ne possédons que les écrits de ceux qui prônaient une vie moins austère fondée sur la prajñā ou connaissance spéculative et discernante du dharma. Par nature, les bhikṣu āranyaka n'avaient ni le souhait ni les moyens matériels de rédiger quelque traité que ce fût sur leur propre démarche ascétique et transmettaient leur savoir de maître à disciple par oralité. Ce que nous savons d'eux provient donc de sources dont les auteurs décriaient les pratiques ascétiques qu'ils considéraient comme extrêmes.

Ainsi la pratique de rétention du souffle respiratoire, par exemple, fut-elle rejetée par les tenants de la prajñā des écoles du sthaviravāda. Dans le Mahārāhulovādasutta ${ }^{60}$, c'est encore une fois Śariputra qui conseilla à Rāhula la méthode respiratoire adéquate afin de vivifier sa pratique de l'attention correcte (samyaksmṛti), septième auxiliaire de l'octuple chemin. Il ne s'agit nullement ici de procéder à des techniques yogiques fondées sur la capacité à maîtriser la rétention de la respiration telle qu'elle est mentionnée par l'auteur de la Bhāgavad Gìt $\bar{a}^{61}$ ou par Patañjali au sujet du prāṇāyāma ${ }^{62}$, mais à développer l'attention de la respiration (ānāpānasati) : " Ici, ô Rāhula, un bhikṣu, s'étant rendu dans la forêt ou au pied d'un arbre ou dans une hutte vide, qui s'assoit, après avoir croisé ses jambes, tenu son corps droit et porté son attention devant lui, toujours avec attention, il inspire, avec attention, il expire ${ }^{63}$. Ce qui est donc mis en avant dans la pratique est l'attention portée à l'agir, une attention ouvrant le bhikṣu à la connaissance des mécanismes de production des désirs et des moyens de les enrayer. De même le jeûne ascétique, qui pouvait mener certains ascètes à une dénutrition et à un état

60. PTS, MN, vol. 1, sutta 62, p. 420-426.

61. «D'autres sacrifient le souffle expiré dans le souffle inspiré, d'autres encore le souffle inspiré dans le souffle expiré, arrêtant le cours de l'inspiration et de l'expiration et ayant pour objectif final la protraction du souffle. », apāne juhvati prāṇaṃ prāṇe 'pānaṃ tathāpare prāṇāpānagatī ruddhvā prāṇāyāmaparāyaṇāḥ, BhG 4.29-30.

62. «La protraction du souffle est l'interruption du cours de l'inspiration et de l'expiration », śvāsapraśvāsayor gativicchedaḥ prānāyāmaḥ, YS 2.49.

63. idha rāhula bhikkhuvarañnagato vā rukkhamūlagato vā suññāgāragato vā nisīdati pallan̉kaṃ ābhujitvā ujuṃ kāyam paṇidhāya parimukhaṃ satị̣ upațthapetvā so sato va assasati sato passasati. PTS, MN, vol. 1, sutta 62, p. 425. 
anorexique ${ }^{64}$, fut réglementé dans les Vinaya du saṃgha par l'observance de l'uposatha durant les phases de pleine et de nouvelle lune. Quant à la direction à donner à la pensée, elle était pleinement tournée, non pas vers l'arrêt de son activité, mais vers la pratique exclusive de la concentration (dhyāna) qui ouvrait le bhikșu à un stade de conscience ni pénible, ni agréable, à la pureté absolue d'impassibilité et d'attention (upekșāsmṛtipariśuddhi) qui préfigurait, selon les écoles anciennes bouddhiques, l'état définitif opéré par le nirvānạa.

\section{Conclusion}

Comme pour nombre d'épisodes de la vie du fondateur, celui narrant les six années d'austérités passées dans la solitude et les souffrances a donc une longue histoire rédactionnelle et fit l'objet de multiples interprétations en fonction des milieux bouddhiques qui l'ont transmis. S'il semble condamner les pratiques ascétiques des śramanes et des brāhmanes, il eut pour fonction première d'éviter au sein du saṃgha une trop forte influence du courant bouddhique forestier ou āranyaka. Qu'il y ait eu des virtuoses de l'ascétisme dans la communauté, cela paraît certain. Que le fondateur n'ait pas eu les mêmes inclinations ascétiques, ni tenu les mêmes propos rigoristes au cours de sa vie, notamment vers la fin de celle-ci, cela est confirmé par les tensions évoquées dans le récit du concile de Rājagṇha, historique ou fictif, et, notamment, entre les disciples Ānanda et Kāśyapa. Mais que ces virtuoses en vinssent à briser (bhid-) la communauté par leur attitude envers les śrāvaka ou à entraîner d'autres bhikṣu dans leur rigorisme ascétique, cela n'était nullement acceptable. L'histoire des schismes (saṃhabheda) montre bien que les dissensions reposaient sur des dénonciations de règles disciplinaires adjointes ou de laxisme, dès le vivant du fondateur comme immédiatement après sa mort, voire plus tard telle la scission communautaire entre les Sthaviravādin et les Mahāsāṃghika au IV ${ }^{\mathrm{e}}$ s. av. J.-C. S'il n'est

64. «D'autres, réduisant leur nourriture, sacrifient leurs souffles vitaux dans leurs souffles vitaux. Et tous [ces ascètes] ont la notion vraie du sacrifice et, par le sacrifice, leurs impuretés [morales] sont détruites. », apare niyatāhārāḥ prāṇān prāṇeșu juhvati sarve 'py ete yajñavido yajñakșapitakalmașāḥ, BhG 4.30. 
guère possible de définir à quel moment cet épisode fut construit, la période la plus propice à son développement fut certainement celle durant laquelle les écoles bouddhiques purent s'implanter durablement dans des structures monastiques pérennes à savoir entre le temps du règne du roi Aśoka et le $\mathrm{I}^{\mathrm{er}} \mathrm{s}$. av. J.-C., date à laquelle celui-ci était déjà représenté sur le toraṇa est du stūpa de Sāñcī, période faste de l'histoire du bouddhisme où la vie cénobitique s'éloigna considérablement de la vie d'errance. Les śrāvaka des écoles du sthaviravāda, qui se sédentarisèrent par la construction de saṃghārāma de plus en plus complexes et étendus qui nécessitaient, en outre, une logistique de fonctionnement et d'entretien importante, ne manquèrent pas d'orienter la portée signifiante de cet épisode afin de maintenir leur propre champ d'action, à savoir le développement de la pensée par la récitation des Sütra et la pratique de dhyāna. Mettant l'accent sur un mode de vie communautaire moins austère que celui des bhikṣu āraṇyaka, l'épisode qui visait à illustrer l'un des deux extrêmes rejeté par la voie moyenne et à réfuter tout avantage propre aux mortifications face à la pratique de la prajñā et des quatre étapes de dhyāna, n'a pu cependant être placé, dans l'économie de la vie du fondateur, qu'avant son éveil. Son ou ses auteurs défendirent alors l'idée que la voie vers l'éveil devait passer non pas par le développement du corps (kāyabhāvana), mais par celui de la pensée (cittabhāvana). Ainsi furent opposés, dans les écoles des sthaviravādin, le corps de Śākyamuni vivifié par le tapas sans pour autant devenir un corps vivifiant, et le corps du Buddha, vivifié par la mesure et par le bonheur (sukha) séparé des désirs et des choses mauvaises, qui le conduisit à la connaissance (jñāna) et, de là, à l'obtention d'un corps nirvānéé.

Cette conception au fondement de la construction de l'épisode contraignit les tenants du mahāyāna, qui récrivirent la vie du Buddha en fonction de la carrière propre au bodhisattvayāna, à donner une autre signification à ces six années d'ascétisme. L'auteur du Lalitavistara, par exemple, se vit obligé, certes, de conserver cette histoire traditionnelle, mais d'en donner un tout autre sens. Comment le Tathāgata omniscient, aurait-il pu, en effet, ne pas avoir eu la pleine conscience de l'inanité de telles pratiques ascétiques auxquelles il se livra néanmoins durant six longues années? La réponse était évidente. Non seulement il avait 
eu conscience de l'inutilité de telles pratiques, mais plus encore il s'y était livré par compassion afin de révéler cette inanité à la vue de tous, des dieux et des hommes, réfutant ainsi toute autre voie que celle du véhicule des bodhisattva. Inversement, dans l'histoire du bouddhisme, où qu'il se fût implantét ${ }^{6}$, les dénonciations récurrentes du laxisme des bhikṣu, dû à la nature humaine mais aussi en partie à la théorie de l'anātman et de l'impermanence de tout dharma, eurent parfois pour conséquence de revendiquer un retour à un idéal d'ascétisme. La naissance du mahāyāna, de ses dix perfections de la prajñā portées à leur extrême et de ses bodhisattva forestiers, issus des milieux laïcs, en aurait été en partie une conséquence directe ${ }^{66}$. L'épisode de la pratique des six années d'austérités, le mode de vie originel des premiers grands disciples $\mathrm{du}$ fondateur, les récits hagiographiques des pratyekabuddha et leurs exploits ascétiques furent autant d'exemples à suivre et perpétuèrent au sein même du saṃgha cette dichotomie entre développements du corps et de la pensée. La finalité première de la construction de la figure émaciée de Sākyamuni n'arrêta finalement pas ceux d'entre les bouddhistes qui considérèrent que la voie vers l'extinction (nirvāṇa), voire vers l'éveil (bodhi), fondée sur la connaissance des quatre nobles vérités, devait aussi passer par celle de la pratique corporelle des austérités.

gducoeur@unistra.fr

65. Au III ${ }^{\mathrm{e}}$ s. apr. J.-C., en Chine du Sud, les taoïstes n'avaient guère de considération pour ces bhikṣu qui «sont plongés dans les plaisirs de l'alcool, certains entretiennent femme et enfants, ou spéculent sur les biens, ou encore consacrent toutes leurs forces à tromper le monde », Meou-Tseu, Dialogues pour dissiper la confusion, traduction, introduction et notes par Béatrice L'Haridon, Paris, les Belles Lettres, 2017, p. 35.

66. Daniel Boucher, Bodhisattvas of the Forest and the Formation of the Mahāyāna : A Study and Translation of the Rāsțtrapālapariprcchā-sūtra, Honolulu, University of Hawai'i Press, 2008. 


\section{Śākyamuni émacié}

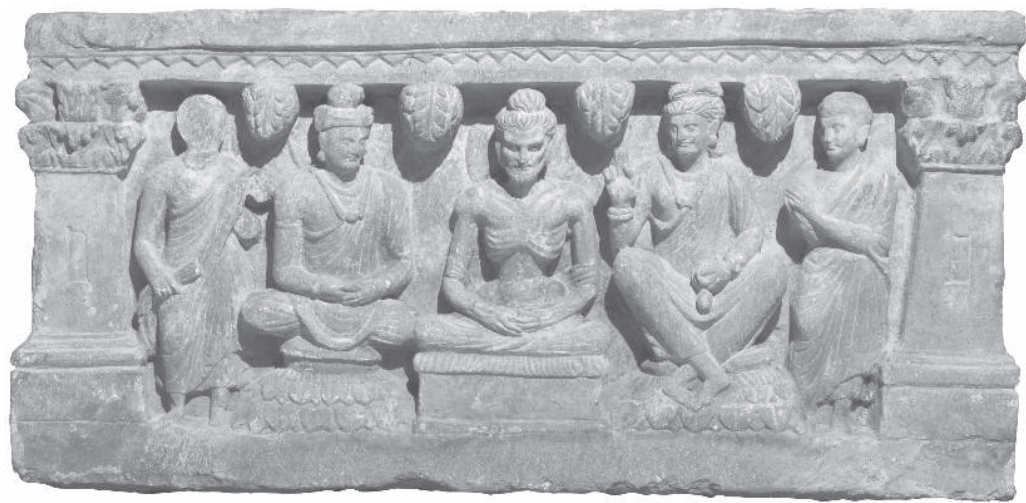

Fig. 1 : Śākyamuni pratiquant les mortifications entouré de Śakra-Indra (à gauche) et de Brahmā (à droite).

Schiste $18 \times 37 \mathrm{~cm}$. Gandhāra ( $\mathrm{II}^{\mathrm{e}}-\mathrm{III}^{\mathrm{e}}$ s. apr. J.-C.). Collection privée, Londres (Photo O. Bopearachchi).

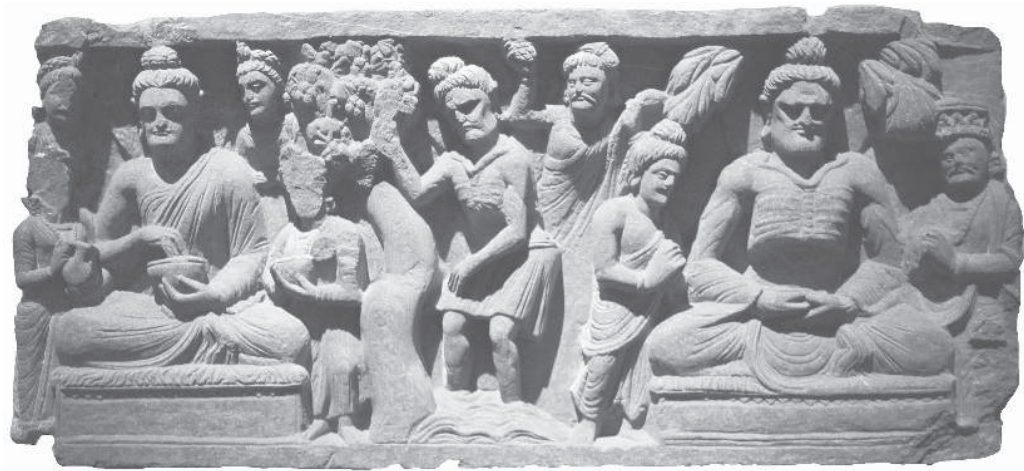

Fig. 2 : Śākyamuni pratiquant les mortifications (à droite), les abandonnant (au centre), puis acceptant la nourriture offerte par Sujātā (à gauche).

Schiste $30 \times 68 \mathrm{~cm}$. Gandhāra ( $\mathrm{II}^{\mathrm{e}}-\mathrm{III}^{\mathrm{e}}$ s. apr. J.-C.). Museum für Indische Kunst, Berlin (Photo O. Bopearachchi). 

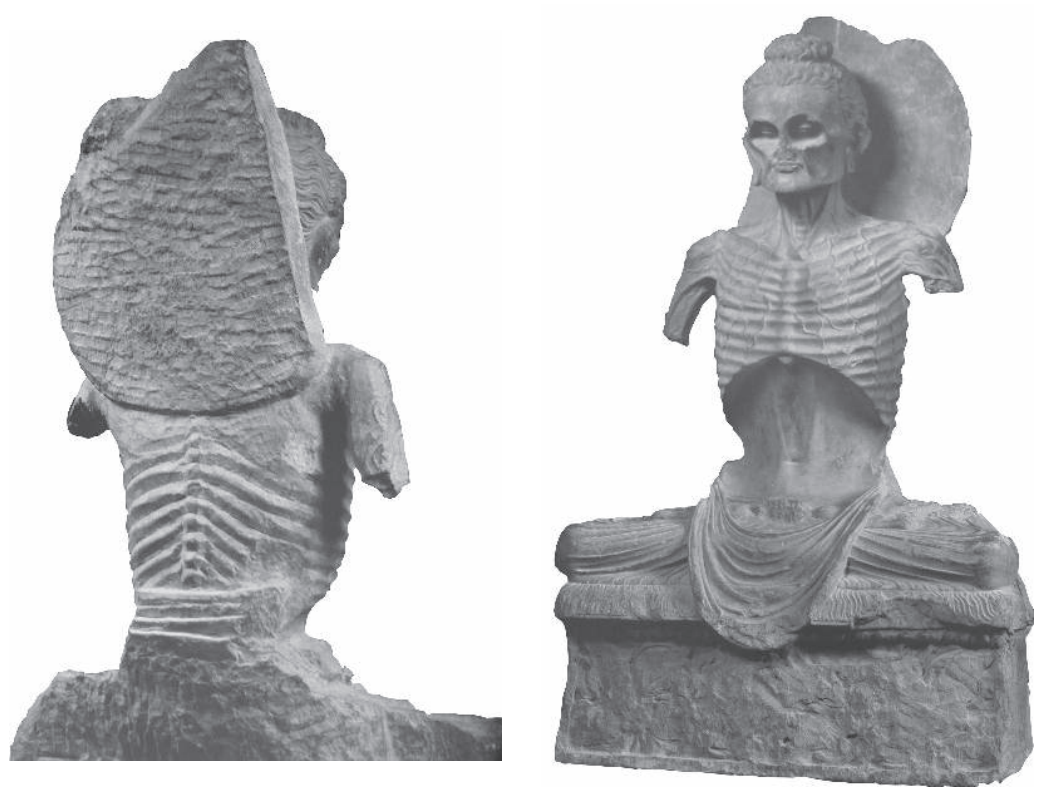

Fig. 3 : Śākyamuni émacié.

Gandhāra (II ${ }^{\mathrm{e}}-\mathrm{III}{ }^{\mathrm{e}}$ s. apr. J.-C.).

D’après Nancy Wiener Gallery, New York. 

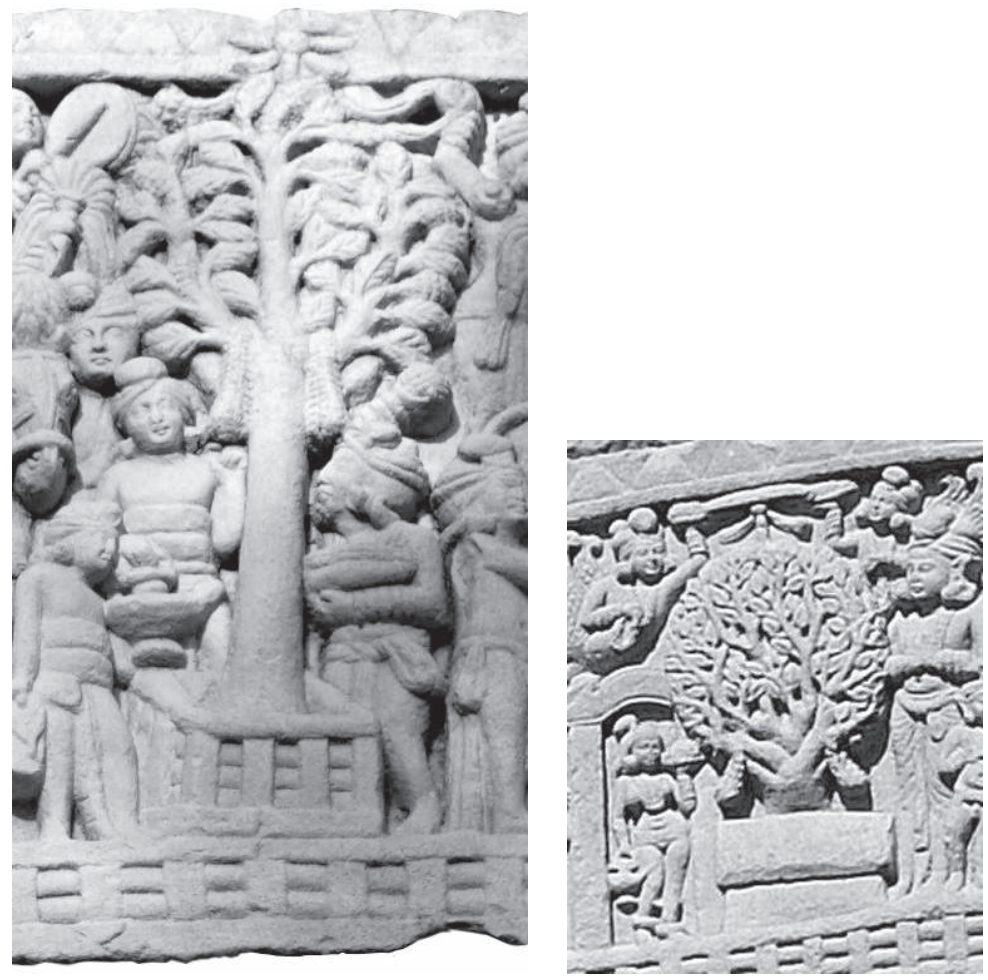

Fig. 4 : Sujātā offrant de la nourriture.

À gauche : Sujātā se tient à droite de l'arbre de l'éveil symbolisant le Buddha.

Toraṇa est du stūpa de Sāñcī, I ${ }^{\text {er }}$ S. av. J.-C. (photo O. Bopearachchi).

À droite : Sujātā se tient à gauche de l'arbre de l'éveil symbolisant le Buddha.

Toraṇa nord du stūpa de Sāñcī, I ${ }^{\text {er }}$ s. av. J.-C. (photo O. Bopearachchi). 